\title{
LABORATORY, SOCIETY, TRAUMA "VECTORS" (CONSEQUENCES), PARTS OF NON-EUCLIDEAN TRIANGLES
}

\author{
Admir Nake ${ }^{*}$ \\ I*University of Medicine, Tirana, Albania;
}

*Correspondent author Admir Nake, email: adi.nake@ yahoo.com;

Received May, 2018; Accepted May, 2018; Published June, 2018;

DOI: https://doi.org/10.31407/ijees8327

UOI license: http://u-o-i.org/1.01/ijees/09428734

\begin{abstract}
Introduction: Traumatic experience is not only physical and psychological, but and social. Social, psychological and physical traumas are communicative vessels that have a significant impact on each other, so the medical, but and non-medical attitude needs to be improved in these three directions. Recent laboratory achievement, new technology and best management approaches are tools that can converge in simple and efficient mechanisms. Aim: Recommendations and steps, to improve trauma situations, based mainly on psychosocial, laboratory approaches, individual features and risk factors for trauma, in the context of new technology, and recent researches developments. Material and Methods: Latest literature. Results: Study of risks for trauma and trauma events mechanisms highlights recently laboratory biomarkers importance. Dynamic evaluation under the specific conditions, impose application of more and more efficient algorithms, including social context and social trauma. Conclusions: 1. Progress, ending prolonged transition period, brings the cure or prevent different types of social trauma 2. If we see our laboratories, societies, traumas "vectors"(consequences), as parts of non-Euclidean triangles, we can arrive at a new multidisciplinary consensus and more successful attitude about trauma as the cardiologists did with atherosclerosis and Framingham criteria or the diagnosis of the Acute Myocardial Infarction, at the turn of the millennium, who gave the place belonging to the troponin, or CK( creatin kinase) with CK-MB( CK isoenzyme).
\end{abstract}

Key words: trauma, laboratory, society, recently biomarkers 